\title{
Effect of Fiber Loading and Compatibilizer on Rheological, Mechanical and Morphological Behaviors
}

\author{
Inul Azianti Noranizan, Ishak Ahmad* \\ School of Chemical Sciences and Food Technology, Faculty of Science and Technology, \\ Universiti Kebangsaan Malaysia, Bangi, Malaysia \\ Email: "gading@ukm.my
}

Received April 5, 2012; revised May 6, 2012; accepted May 17, 2012

\begin{abstract}
This study presents the composites prepared by melt blending based on high-density polyethylene, containing various amounts of kenaf fiber loadings and polyethylene-grafted maleic anhydride (PE- $g$-MA) in an internal mixer were prepared and investigated. Fourier transform infrared spectroscopy was used to characterize both untreated and treated kenaf fibers. A rheological study of the composites showed a high complex viscosity and dynamic shear storage modulus between untreated and treated composites and composites with compatibilizer. A mechanical test showed that the tensile strength and tensile modulus were optimal with 20\% fiber loading but decreased with 30\% fiber loading for both the untreated and treated composites. The composite with PE-g-MA showed an improved mechanical strength. This phenomenon is due to an increase in the interfacial adhesion between the fiber and matrix leading to an improvement in the compatibility of the blend. Treatment of the kenaf fiber improved in the mechanical and impact strengths in comparison to the untreated kenaf composites. This behavior was supported by a morphology analysis of the fractured surfaces revealed that strong interfaces were formed on addition of the compatibilizer.
\end{abstract}

Keywords: Fiber Treatment; Rheology; Morphology; Mechanical Properties

\section{Introduction}

Great attention has been paid in recent years toward the development natural fibers for plastic reinforcement, the replacement of glass fibers, and use in other synthetic materials owing to an increasing demand for environmental friendly materials $[1,2]$. Biobased products can form the basis for sustainable and environmental friendly materials that can compete in markets currently dominated by petroleum based products $[3,4]$. These fibers offer several advantages including high specific strength and modulus, low cost, low density, renewability, biodegradability, easy fiber surface modification, wide availability and a relative nonabrasiveness [5].

Polyolefins have many applications in daily life and their consumption is continuously increasing. These materials are used extensively for short-term applications such as packaging film, healthcare products, construction materials, automobile, parts, and agriculture and are often disposed off at waste sites [6]. Alternatively, polymer blends and composites containing natural polymers as biodegradable additives (kenaf, jute, sisal, coir, flax, banana, wood flour, rice hulls, pulp and cellulose fibers) have been developed to reduce the lifecycle of compos-

${ }^{*}$ Corresponding author. ites $[7,8]$. These composites are easily extrudable and commercialized. High-density polyethylene (HDPE) is among the widely used polyolefin polymers owing to its high strength, low cost, excellent processability and high chemical resistance $[9,10]$.

The major disadvantage of incorporating a natural polymer into a synthetic polymer is their compatibility. Natural polymers are hydrophilic in nature, whereas synthetic polymers are hydrophobic. The hydrophilic characteristic of natural fibers leads to a high moisture absorption causing dimensional changes in the fibers and resulting in a swelling of the manufactured composite [11-13]. The resultant blends of these two types of polymers are almost immiscible. The poor interaction between the matrix and filler interphase causes weaker mechanical properties [14]. To improve their interaction, modification of both polymers and additives has been conducted. It is well known that a chemical treatment applied to a fiber surface may affect the mechanical properties of the final material. Many studies have been conducted on physical and chemical methods to improve the adhesion between the fiber and matrix through a modification of the fiber and/ or the polymer matrix [15]. Fiber modification includes treatment with silane $(\mathrm{Si})$, acetic anhydride (Ac), styrene (S), maleic anhydride 
(MA), alkali, etc [16,17]. Hydroxyl and other polar groups located in the branched heteropolysaccharides present in the kenaf fiber (KF) and in the active sites of the water absorption results in an incompatibility with the hydrophobic HDPE matrix which in turn leads to poor composite properties. To reduce the surface hydrophilicity, the surface of the fiber is coated with MA groups that can form an ester linkage [18-20].

In the present study, a systematic investigation was conducted on the effect of fiber loading to obtain the thermal, rheological and morphological properties of the polyethylene composites. The composites were prepared through melt blending process and their mechanical strength and rheological behaviors, including their morphology, were studied. The general objective of this study was to investigate the potential of an untreated kenaf fiber (UKF) and a treated kenaf fiber (TKF) for the production of kenaf-HDPE composites.

\section{Experimental}

\subsection{Materials}

HDPE with a density of $0.94 \mathrm{~g} \cdot \mathrm{cm}^{-3}$ was supplied by Commercial Plastic (M) Sdn. Bhd and KFs (Hibiscus cannabinus) with a density of $1.20 \mathrm{~g} \cdot \mathrm{cm}^{-3}$ were purchased from KFI Sdn. Bhd. The fibers were ground using an Ika Werke MF10 heavy-duty grinder (Staufen, Germany) to obtain $3 \mathrm{~mm}$ long fibers. Sodium hydroxide $(\mathrm{NaOH})$ was used for the surface treatment and maleic anhydride was supplied by Merck Schuchardt OHG, Hohenbrunn, Germany-as a coupling agent.

\subsection{Modification of the Kenaf Fibers}

The KFs were immersed in a $6 \% \mathrm{NaOH}$ solution for $3 \mathrm{~h}$ at room temperature to eliminate pectin and hemicelluloses [5,21]. After alkalization treatment, the fibers were thoroughly washed with running distilled water and allowed to dry at room temperature for $48 \mathrm{~h}$ [22]. The fibers were then esterified for $25 \mathrm{~h}$ with MA dissolved in boiling acetone at $52^{\circ} \mathrm{C} \pm 0.5^{\circ} \mathrm{C}$. Finally, the fibers were washed several times in cold acetone and distilled water.

\subsection{Melt Blending Processing}

HDPE/KF composites were prepared through melt blending in a Haake Rheomix 600 p mixer using roller blades and a mixing chamber with a volumetric capacity of 69 $\mathrm{cm}^{3}$ at $170^{\circ} \mathrm{C}$. The rotor speed was fixed at $50 \mathrm{rpm}$ and the mixing time was 15 minutes $[23,24]$. In all samples, the KFs were preheated for 3 min before mixing. The sample preparation was carried out in two stages. In the first stage, the UKF and TKF were mixed along with HDPE at different weight percents of fiber loading (10\%, $20 \%$ and $30 \%$ ). In the second stage, polyethylene-grafted maleic anhydride (PE- $g$-MA) at different weight percents $(4 \%, 8 \%, 12 \%$ and $16 \%)$ was mixed with optimum amount of HDPE/UKF and HDPE/TKF from the first stage. Subsequently, these mixtures were compression molded using a Carver hydraulic press, model 2697, to produce $(1 \pm 0.1) \mathrm{mm}$ and $(3 \pm 0.1) \mathrm{mm}$ thick sheets at $170^{\circ} \mathrm{C}$. For tensile testing, the nominal sample thickness was $(1 \pm 0.1) \mathrm{mm}$, whereas the nominal thickness for the impact strength was $(3 \pm 0.1) \mathrm{mm}$.

\subsection{Fourier Transform Infrared Spectroscopy (FTIR)}

The UKF and TKF spectra were characterized using an FTIR spectrometer quenched using a diffuse reflectance unit (DRIFT, Perkin Elmer 2000). The FTIR spectra were recorded with one spectrometer; the powdered samples were dispersed in $\mathrm{KBr}$, and thin disks were prepared and analyzed in transmission mode. An infrared spectrum of 4000 to $600 \mathrm{~cm}^{-1}$ was obtained by performing 200 scans at a resolution of $4 \mathrm{~cm}^{-1}$.

\subsection{Rheological Properties}

The thermal behavior of the polymers was measured using an Anton Paar Physica MRC 301 dynamic rotational rheometer (Anton Paar GmbH, Graz, Austria) operating in strain-controlled mode. A $25 \mathrm{~mm}$ plate geometry with a $51 \mu \mathrm{m}$ gap size was used. The dimensional changes in the geometry during measurements were taken into account by controlling the gap size under normal force and measuring the size with a TruGap induction sensor. The viscosity was obtained using a shear rate gradient of 0.05 $\mathrm{s}^{-1}$ to $500 \mathrm{~s}^{-1}$ with a dynamic mode frequency sweep (strain control) process at $170^{\circ} \mathrm{C}$. The moduli and complex viscocities were recorded. The specimens used in the rheometer were compress moulded using a hydraulic press at $150^{\circ} \mathrm{C}$ for $15 \mathrm{~min}$ and $(1 \pm 0.1) \mathrm{mm}$ thick were cut from those samples [25].

\subsection{Mechanical Testing}

The composites were prepared to evaluate the effects of both fiber and compatibilizer loading on their mechanical properties. The samples were prepared according to the ASTM-D 638 and ASTM-D 256 procedures. All samples for tensile testing were cut into dumbbell-shapes using a hollow die punch with a 6051/0000 specification. The tensile test was performed according to the ASTM-D 638, procedure using universal tensile machine (model 5560) connected to a PC for data acquisition. A crosshead speed of $50 \mathrm{~mm} / \mathrm{min}$ and a gage length of $40 \mathrm{~mm}$ were used to carry out the test. The impact strength was determined from the specimens with dimensions of $63.5 \times$ $12.7 \times 3 \mathrm{~mm}^{3}$ using a Tinius Olsen testing machine 
(Model IT504) according to the ASTM-D 256 with a notch angle of $45^{\circ}$ and a "V" notch depth of $2.54 \mathrm{~mm}$. Ten replicated specimens of each composition were tested. The resulting average data along with the standard deviation are reported.

\subsection{Morphology Study}

The fractured surfaces of the composites were examined using a ZEISS SUPRA-55 VP Field Emission Scanning Microscope (LV FE-SEM). The tensile fractured surfaces of the composite specimens were gold sputtered (50 nm thickness) and dried for half an hour in a vacuum at $100^{\circ} \mathrm{C}$ prior to study to avoid charging. Observations were made on the cross sections of the fractured surfaces of the gold sputtered samples, all of which were prepared by testing the tensile performance.

\section{Results and Discussions}

\subsection{FTIR Analysis}

The FTIR spectra of (a) the untreated kenaf fiber, (b) an alkali-treated sample, and (c) KF treated with alkali and MA (TKF) are shown in Figure 1. The KF spectrum shows hydrogen bond $\mathrm{O}-\mathrm{H}$ stretching absorption around at $3400 \mathrm{~cm}^{-1}$ and a prominent $\mathrm{C}-\mathrm{H}$ stretching absorption at around $2900 \mathrm{~cm}^{-1}$ (Figure 1). The peak intensity at $3421 \mathrm{~cm}^{-1}$ decrease in both the alkali treated sample and TKF due to esterification. In the fingerprint region, between 1800 and $900 \mathrm{~cm}^{-1}$, many sharp and discrete absorption bands appear owing to the functional groups present in the KF. The absorption at $1732 \mathrm{~cm}^{-1}$ in UKF is assigned to the carbonyl stretching of the acetyl groups of hemicelluloses and the peak at $1248 \mathrm{~cm}^{-1}$ represents the $\mathrm{C}-\mathrm{O}$ stretching of the acetyl group of lignin. The peak at around $1630 \mathrm{~cm}^{-1}$ represents the $\mathrm{C}=\mathrm{O}$ of the hemicelluloses [21].

The observation in Figure 1 shows that the peaks at 1730 and $1248 \mathrm{~cm}^{-1}$ disappear in both the alkali-treated sample and the TKF. This shows that hemicelluloses and lignin are partially removed from the fiber surface of both materials. Lignin is a cementing agent that ultimately holds the fiber together in bundles. The band at 1048 to $1037 \mathrm{~cm}^{-1}$ in Figure 1 is assigned to the $\mathrm{C}-\mathrm{O}$ stretching in cellulose, hemicelluloses, and lignin, or to the $\mathrm{C}-\mathrm{O}-\mathrm{C}$ stretching in cellulose and hemicelluloses. The small sharp band at $888 \mathrm{~cm}^{-1}$ originated from the $\beta$-glucosidic linkages between the sugar units in the hemicelluloses and cellulose. In comparison, the TKF spectrum provides evidence of maleation, as indicated by the presence of important ester bands at 1627 and $1037 \mathrm{~cm}^{-1}$.

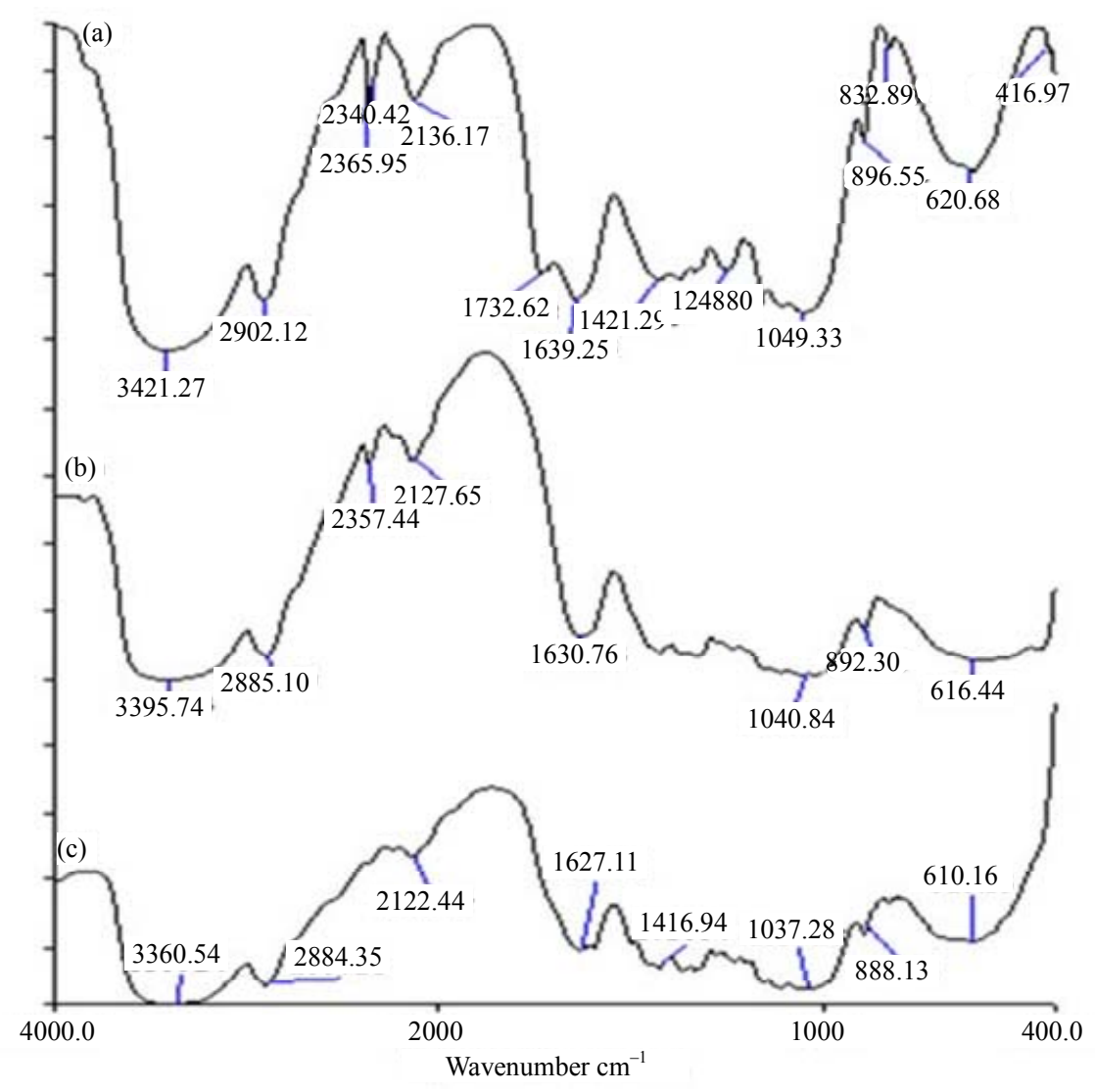

Figure 1. FTIR spectra for (a) UKF; (b) Alkali-treated sample; and (c) TKF. 
As expected, the absence of an absorption region from 1850 to $1750 \mathrm{~cm}^{-1}$ in the TKF spectrum confirms that the products are free of unreacted maleic anhydride.

\subsection{Rheological Analysis}

Melt rheology of thermoplastic blends is vital in understanding the relationship between their structural proper-

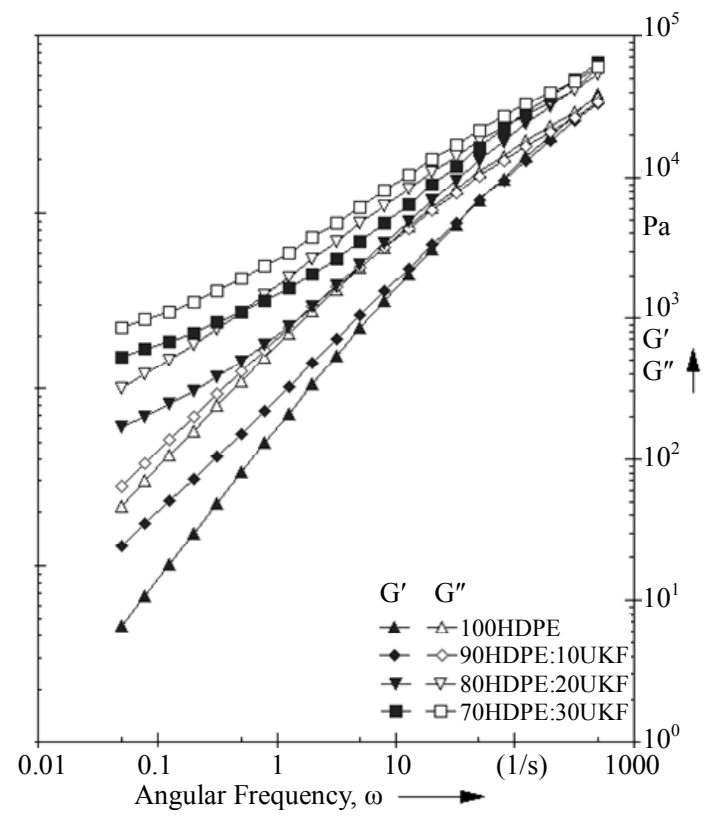

(a)

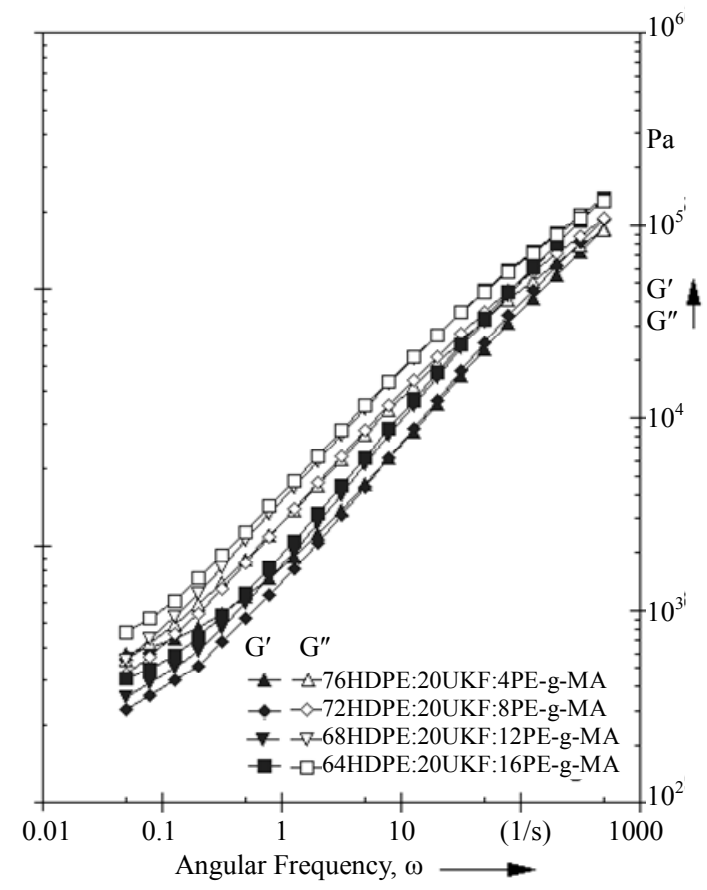

(c) ties and their processability. The presence of a stable viscoelastic region was confirmed over time and through a strain sweep experiment before a frequency sweep. The results show that both the HDPE/UKF and HDPE/TKF samples were within the linear viscoelastic region. Figures 2(a) and 2(b) show the dynamic shear moduli of untreated and treated composites at whereas Figures 2(c) and

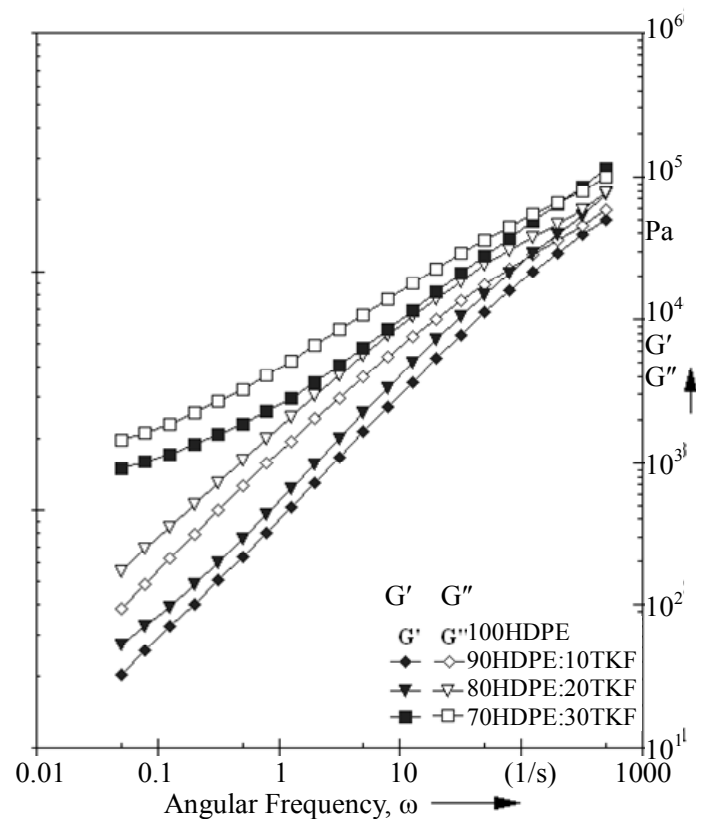

(b)

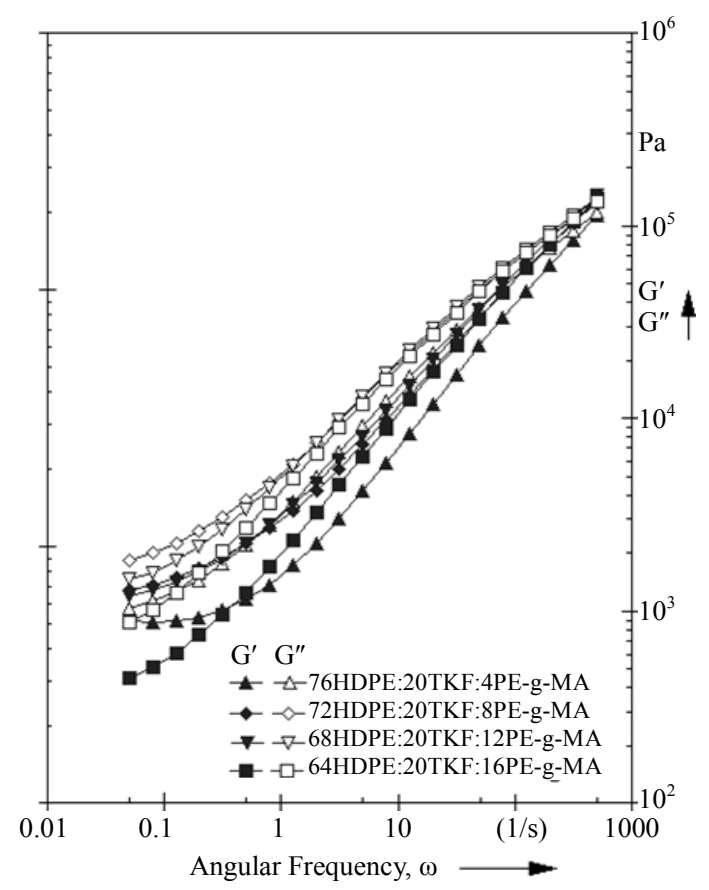

(d)

Figure 2. Dynamic shear moduli (G' and G”) of (a) HDPE/UKF; (b) HDPE/TKF; (c) HDPE/UKF/PE-g-MA; and (d) HDPE/ TKF/PE- $g$-MA. 
2(d) show the dynamic shear moduli of compatibiizer effect composites at $170^{\circ} \mathrm{C}$. The complex viscosities $\left(\eta^{*}\right)$ of these compositions are shown in Figures 3(a) and 3(b). It can be seen in Figures 2 and $\mathbf{3}$ that compositions in the blend affected the values of the elastic modulus $\left(G^{\prime}\right)$, loss modulus $\left(G^{\prime \prime}\right)$ and $\eta^{*}$. These variations in $G^{\prime}$ and $G$ " correspond to energy changes occurring during the dynamic shear process and are strongly dependent on the interaction between polymer interphases in the blend $[9,10]$.

An increase in the $G$ ' and $G$ " values corresponding to an increase in frequency was observed for both the untreated and treated composites (Figures 2(a) and 2(b)). From Figures 2(a) and 2(b), it can be seen that the HDPE/TKF blends show a higher shear moduli than the HDPE/UKF blend. This shows that a strong interaction developed between the polymer-treated fiber interphases. The maleic anhydride forms a network structure between the HDPE-TKF interphases, which enhances the elastic properties of these materials. Compared with the UKF composites, the KF has a poor interaction with HDPE and the components have a weak association with each other. The HDPE/UKF and HDPE/TKF samples with a compatibilizer effect, shown in Figures 2(c) and 2(d), respectively, showed the highest value of elastic modulus in the composites owing to the formation of a filler network through an interaction polymer-filler and fillerfiller. Figures 2(c) and 2(d) show the frequency dependency of $G$ ' for all samples; at low frequencies there is an increase in $G$ ' for all samples. At a high frequency, which is related to polymer chain movement at a small time scale, there are no marked differences among the samples, and therefore, the addition of the filler does not affect the chain movement. Previous studies have shown that slow changes in $G$ ' at low frequencies are related to a solid-like behavior due to the structuration of the filler into the polymer matrix [19]. Apart from the treatments, the addition of PE-g-MA as a compatibilizer lowered $G^{\prime}$ and $G^{\prime \prime}$ in the composites (Figures 2(c) and 2(d)), as PE- $g$-MA leads to the creation of a thin and irregular polymer layer, which assists in the formation of a plastic deformation zone around the fiber [26].

Figures 3(a) and 3(b) show the complex viscosities of all composites. This figure shows that the complex viscosity $\left(\eta^{*}\right)$ increased along with an increase in fiber loading in the blend and decreased with an increase in frequency. This is due to the strong shear thinning behavior of the blend in a molten state. The formulations with a maleic anhydride crosslink have a higher $\eta^{*}$ than the formulations without a maleic anhydride crosslink. This behavior might be due to the formation of a network structure, which causes greater resistance under a shear flow. Furthermore, the amount of KF loading also increased the value of $\eta^{*}$ in both formulation types. In the HDPE/UKF formulations, a greater amount of KF loading will cause a greater entanglement of the chains and thus gradually increase $\eta^{*}$ [27]. It has been reported that $\eta^{*}$ increases when fillers are added to a polymer matrix [28], it can be seen in Figures 3(a) and 3(b) that all composite samples have a higher $\eta^{*}$ than a virgin polymer.

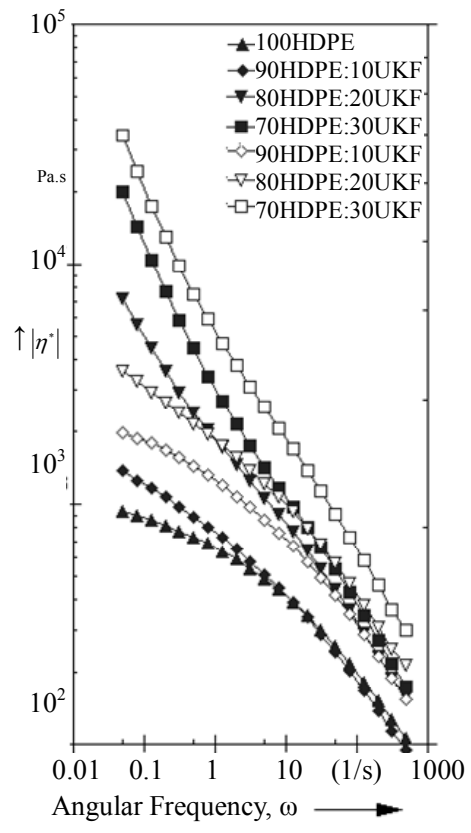

(a)

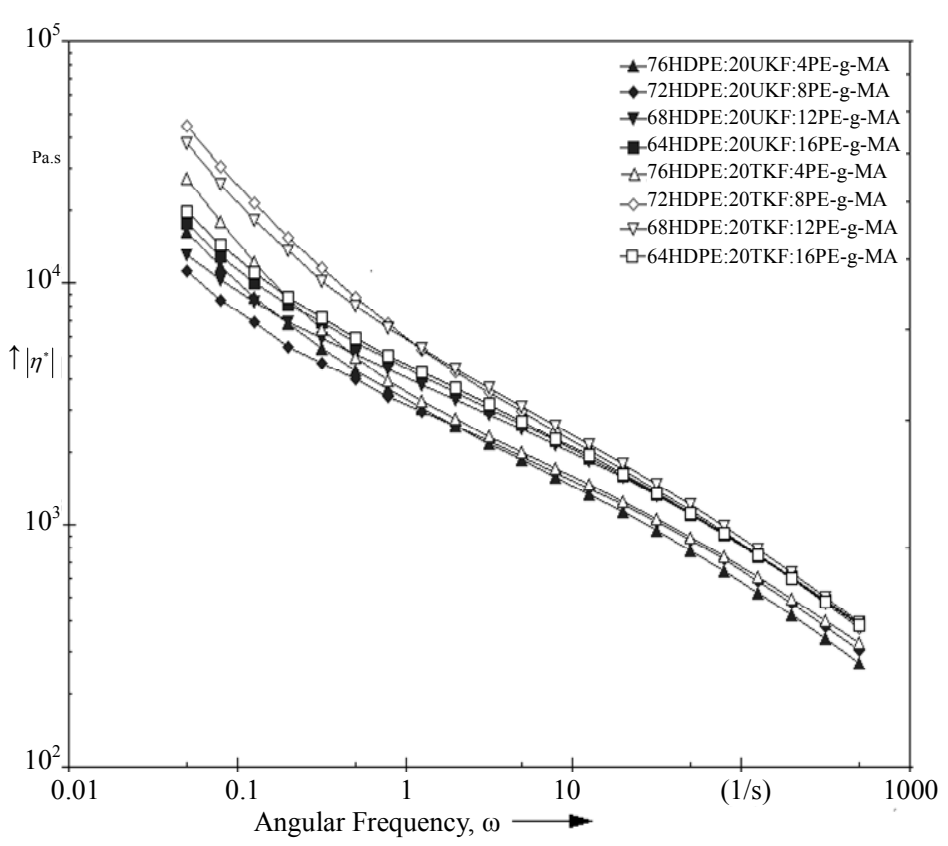

(b)

Figure 3. Complex viscosity $\left(\eta^{*}\right)$ of (a) HDPE/UKF and HDPE/TKF composites and (b) HDPE/UKF/PE-g-MA and HDPE/ TKF/PE-g-MA composites. 
The high aspect ratio of the fillers explains the increase in $\eta^{*}$. Figure 3(b) shows the value of $\eta^{*}$ vs. frequency for composite addition using a compatibilizer. The value of $\eta^{*}$ clearly higher in PE-g-MA than in composites without a compatibilizer, as the rheology behavior is very sensitive to the molecular structure. In addition, PE-g-MA has pendant groups in its backbone and may have a lower molecular weight owing to $\beta$ scission suffered during the grafting process, which was previously studied [19].

The incorporation of fibers in polymer systems generally increases the value of $\eta^{*}$, which continues increasing with fiber loading. At low fiber loading, the viscosity is expected to increase rapidly owing to collisions between particles as they become packed more closely together. The increase in $\eta^{*}$ is found to be more predominant at lower shear rates as the fiber and polymer molecules are not completely oriented. The addition of a fiber to a polymer system will perturb the normal flow of the polymer and hinder the mobility of a chain segment in the flow. As the fiber loading increases, the phenomenon becomes more predominant and, a further increase in the viscosity occurs. In Figure 3(a), we can see that the viscosity of the HDPE-KF composites increases proportionally with the fiber loading at $170^{\circ} \mathrm{C}$. The incorporation of fibers into the HDPE may introduce two effects: 1) increased fiber-matrix interaction, which increases $\eta^{*}$; and 2) increased wall-slips due to the presence of longitudenally oriented fibers along the wall melt interface, which decreases $\eta^{*}$. As the fiber loading or the temperature increases, either a balance is created, giving a constant $\eta^{*}$, or one dominates over the other and increases the $\eta^{*}$. With $30 \%$ fiber loading, $\eta^{*}$ increases as expected, in which this case the viscosity is governed by a fiber-melt interaction $[14,29]$.

\subsection{Mechanical Properties}

\subsubsection{Effect of Fiber Loading}

Figures 4(a) and (b) showed the effect of KF loading on the tensile strength and tensile modulus of the composites. To investigate its effect on the mechanical properties of the composites, the KF loading ( $\mathrm{wt} \%$ ) was varied from 0 to $30 \%$. In both UKF and TKF loadings of up to $20 \%$, both the tensile strength and tensile modulus increased with an increase in the UKF and TKF loadings, but at a higher fiber loading these properties decreased. Following a slight drop in tensile properties, shown in Figures 4(a) and (b), when $20 \% \mathrm{KFs}$ are added to the system, the tensile strength and tensile modulus increased regularly. This increase in the tensile properties is due to an interaction between the dispersal of the KF particles in the matrixes [27].

The optimum fiber loading is $20 \%$. At higher fiber loadings, a reduction in tensile strength and tensile modulus occurred. The low values of the mechanical properties under a high fiber loading might be due to the presence of large number of fiber ends in the composites, which can initiate a crack and potentially cause composite failure. Furthermore, this was due to more dominant fiber-to-fiber interactions that hindered the stress transfer effectively from matrix to fiber [24]. Based on Figure 4(a), an MA treated fiber composite showed an increase in tensile strength compared to an untreated composite. Tan et al. (2011) explained that during MA treatment, the replacement of hydrophilic $(-\mathrm{OH})$ groups in a fiber with more hydrophobic $(-\mathrm{O}-\mathrm{CO}-\mathrm{CH}=\mathrm{CH}-\mathrm{COOH})$ groups slightly reduces the hydrophilic nature of the fiber. MA treatment seems to improve the fiber-matrix interface by reducing the void volume between the fibers and the matrix [30]. Based on Figure 4(b), the MA treatment provides the highest value of tensile modulus. However, such changes in the values of the tensile modulus were not obvious. Chemical treatments bring about large changes in the fibril structures where the amorphous components can be removed, leading to fiber deformation. The outcome of the tensile test results showed that the treatments cause significant changes to the tensile strength compared to the tensile modulus.

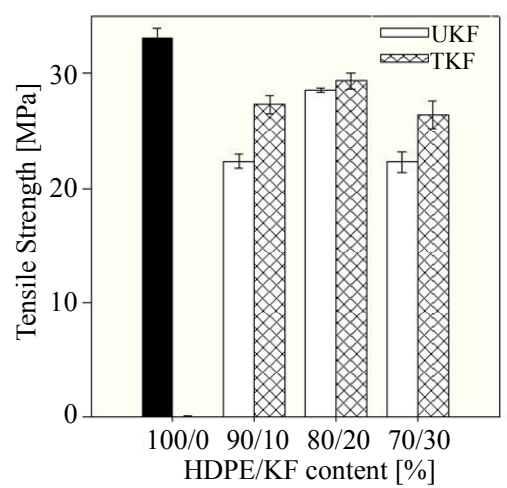

(a)

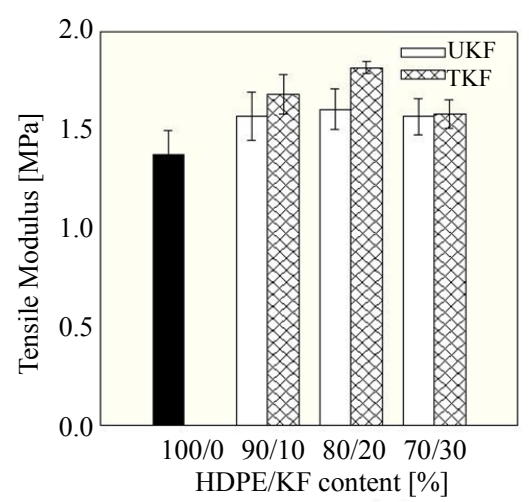

(b)

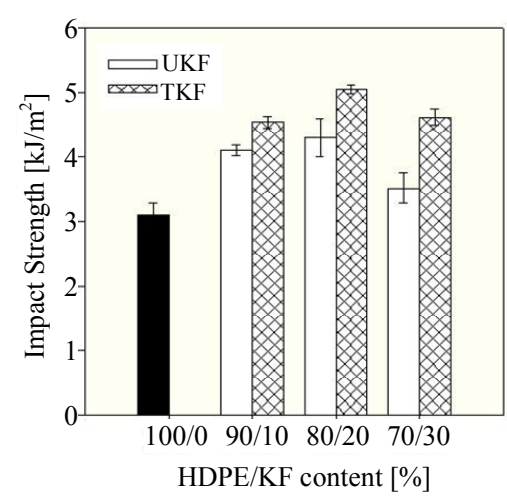

(c)

Figure 4. (a) Tensile strength; (b) Tensile modulus; and (c) Impact strength of HDPE/KF composites. 
The effects of fiber loading on the impact strength of the composites are shown in Figure 4(c). Generally, the increment in the amount of fiber loading increased the impact strength of both the untreated and treated composites compared to the impact strength of the HDPE matrix. This shows that the incorporated fibers act as reinforcements in the composite, and thus, increase the impact properties. As shown in Figure 4(c), the kenaf composite strength gradually increases with an addition of KF of $0 \%$ to $20 \%$. The interaction between the fiber and matrix, which acts as a good impact modifier, increases the impact strength of the composites. This may be due to the existence of the KFs, which are ductile fibers, and to the better fiber-matrix interaction in the system [10]. The results indicate that a KF is capable of absorbing enough energy to stop the crack propagation of the fiber-matrix interphase, which implies that the interaction is sufficiently strong. It is also evident that the HDPE matrix is more compatible with TKF than with UKF owing to the treatment on the fiber surface. In addition, the surface modification of the kenaf fiber (TKF) composites achieved better mechanical properties than that achieved by the surface modification of the UKF composites. The results of the MA treated fiber composites agree with the results by Tan et al. [30], who found that the impact strength for an MA-treated sample was significantly higher than in an untreated sample for a UPR/EFB fiber composite. The impact strength increased as more surface area was covered with MA. This is probably due to a better bridge formation at the interfacial region, either through van der Waals interaction or a covalent bond between the MA and matrix.

\subsubsection{Effect of PE- $g$-MA as a Compatibilizer}

One of the main factors affecting the mechanical properties of fiber-reinforced composites is the adhesion between the fiber and matrix. The use of a compatibilizer can increase adhesion and hence improve the mechanical properties of the composite. Figure 5(a) shows an improvement in tensile strength as the composition of PE- $g$-MA in the composites increases for both UKF and TKF. The tensile strength increases from $25.8 \mathrm{MPa}$ for a system without PE-g-MA to $30.2 \mathrm{MPa}$ with $12 \% \mathrm{PE}-g$ MA in the UKF composites. In contrast, the results show that the tensile strength for the TKF composites increases from 28.2 MPa for a system without PE-g-MA to 33.6 MPa with $12 \%$ PE- $g$-MA. An improvement in the interaction between kenaf-HDPE permits the composite to fracture at a higher fiber loading. The polar PE-g-MA can interact directly with the KF and help reduce the surface tension between the fiber and matrix. The agglomeration of filler particles is minimized and the filler dispersion in the matrix is more homogenous [31].

As implied from the test results shown in Figures 5(a) and 5(b), all treated composites (with 20\% fiber loading) exhibited an improved mechanical strength in compareson to the untreated composites at the same weight percent of fiber loading. The composites prepared with $12 \%$ PE-g-MA loading showed a considerable enhancement in tensile strength and modulus, as shown in Figure 5(b). This phenomenon is probably due to an increase in the interfacial adhesion between the fibers and matrix with the addition of PE-g-MA, particularly for the treated kenaf. It is also believed that the homogeneity of the fiber in the blend increases in the presence of PE-g-MA. In the present study, it is expected that the reactive group, MA, from PE-g-MA will react with the hydroxyl groups of the MA-treated KFs, and that the PE chains will diffuse into the HDPE matrix through interchain entanglements. Hence, the kenaf-copolymer-HDPE interaction will produce a more homogenous mixture. Based on observations of jute-reinforced HDPE composites reported by Mohanty et al., to reduce the surface hydrophilicity, the surface of the fibers should be coated with PE-g-MA. The maleic anhydride groups of PE-g-MA covalently link with the hydroxyl groups of the fibers forming an

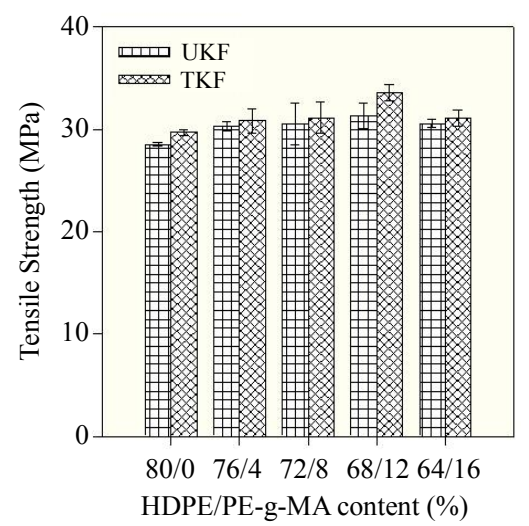

(a)

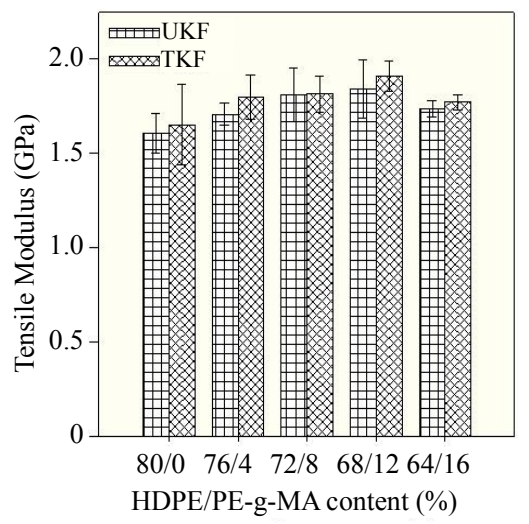

(b)

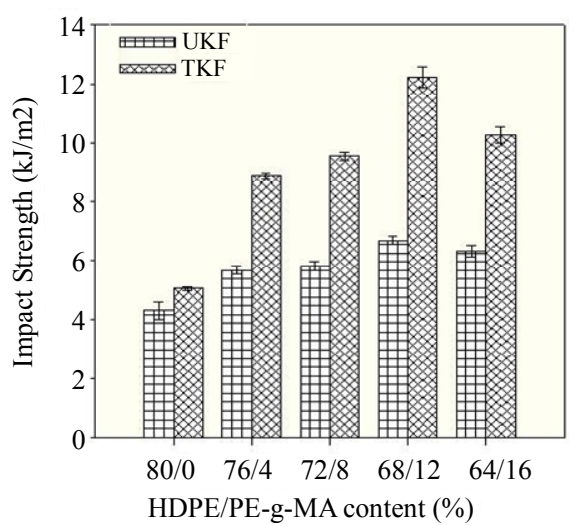

(c)

Figure 5. (a) Tensile strength; (b) Tensile modulus; and (c) Impact strength of HDPE/KF composites. 
ester linkage [18]. Furthermore, the non-polar part (PE) becomes compatible with the HDPE matrix, and lowers the surface energies of the fibers, thereby increasing their dispersion within the matrix. Liu et al. concluded that the maleation of a free hydroxyl group in a fiber with maleic anhydride is an efficient chemical modification for obtaining products with a carboxylic group [32].

Figures 5(a) and (b) also show that the tensile strength and modulus decreased with a $16 \%$ PE- $g$-MA loading suggesting that there is a small stress transfer from the matrix to the fibers. This transfer is due to the critical amount of compatibilizer at which PE-g-MA exhibits the strongest interaction with the fibers as well as with the HDPE matrix. This drop in tensile strength and modulus for untreated composites in the presence of a compatibilizer might also be due to differences in the HDPE morphology.

Figure 5(c) shows that the UKF composites have a lower impact strength than the TKF composites when a compatibilizer is used. An increase in PE-g-MA from 4\% to $12 \%$ in the TKF composites results in some modest property improvements compared to the improvements achieved through the addition of PE- $g$-MA to the UKF composites. This may be attributed primarily to the enhanced interfacial adhesion resulting from the presence of a matrix with increased polarity, which may react or interact favorably with the treated fiber surface. Previous studies reported that higher impact strength can be obtained when there is a better interfacial adhesion between two different polymer types [32].

\subsection{Morphological Properties}

The morphology of the tensile fractured surfaces of untreated and treated composites with $20 \%$ fiber loading without the addition of PE- $g$-MA are illustrated in Figures 6(a) and 6(b), and Figures 7(a) and 7(b) respectively. From Figure 7, it is implied that the HDPE/UKF blends show clear KF particles, which are loosely embedded in the HDPE matrix. In addition, there is a large number of

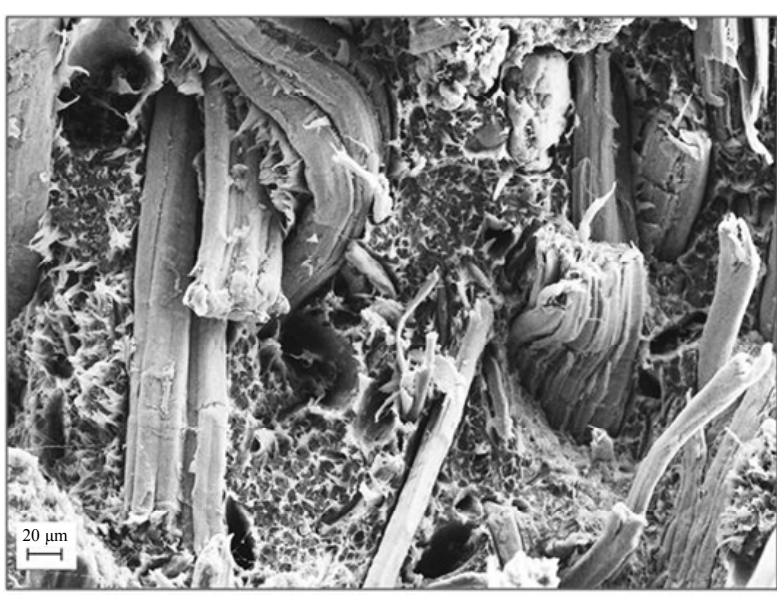

(a)

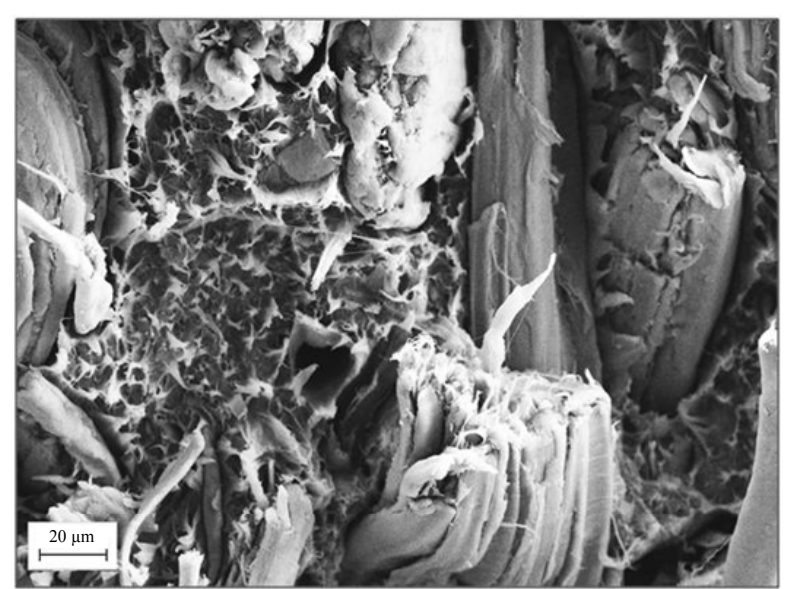

(b)

Figure 6. FESEM micrograph of a UKF composite at (a) $250 \times$ and (b) $500 \times$ magnification.

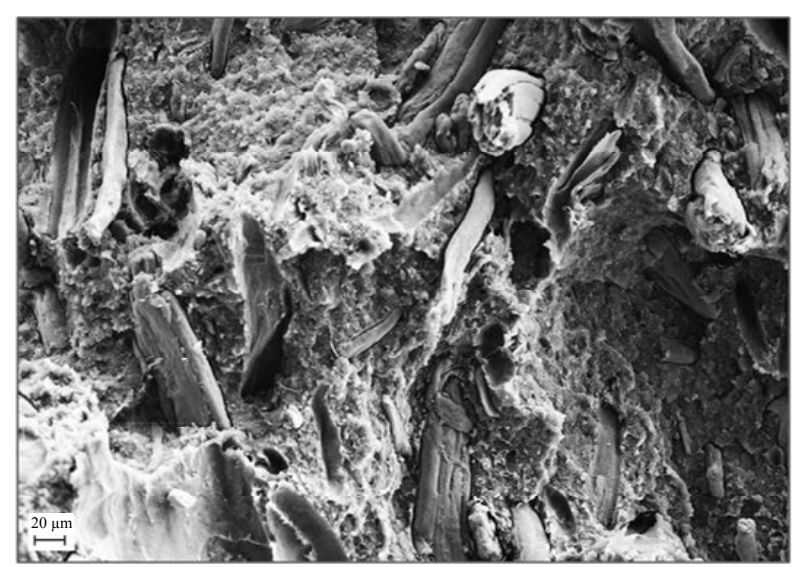

(a)

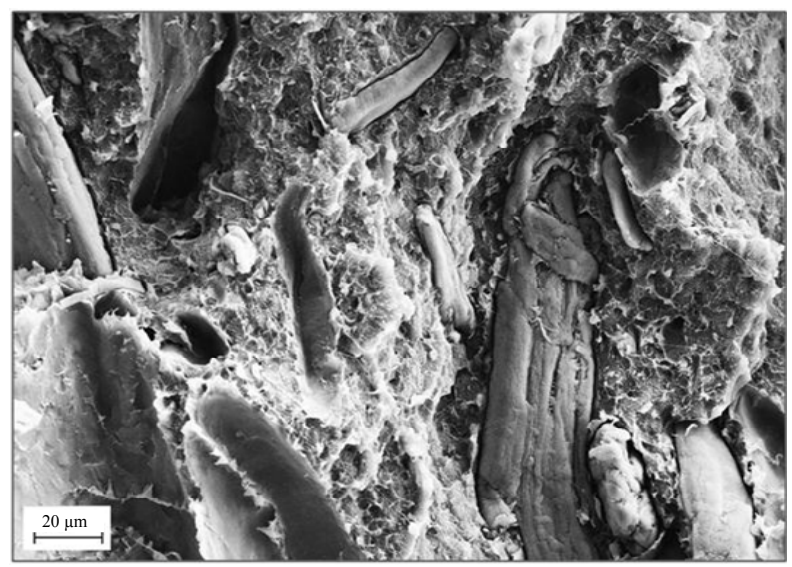

(b)

Figure 7. FESEM micrograph of a TKF composite at (a) $250 \times$ and (b) $500 \times$ magnification. 
gaps between the fibers and matrix, resulting from the pull-out fibers. This indicates poor interfacial adhesion and an inadequate wetting of the UKF within the HDPE matrix, which is probably due to a large difference in the surface energies between the fibers and the matrix. This is the main cause of the lower mechanical properties of these blends. On the contrary, the HDPE/TKF composite shows improved fiber-matrix adhesion. As implied from Figure 7, the TKF composites are coated with layers of a matrix material, which that considerably reduces the gaps between fiber and matrix [17]. As maleic anhydride improves the partial miscibility between HDPE and KF, HDPE appear to adhere to the KF particles very well. The layers of the matrix material were also apparently pulled out along with the fibers during a tensile fracture, which further substantiates the cohesive coupling between the fibers and HDPE [32].

The morphology of the tensile-fractured surfaces of the UKF and TKF composites with $20 \%$ fiber loading and the addition PE- $g$-MA are illustrated in Figures 8(a) and $\mathbf{8 ( b )}$ and 9(a) and 9(b) respectively. It is evident in Figure 9 that the surface with extracted fibers is covered with a layer of both matrixes. The structure is clearly

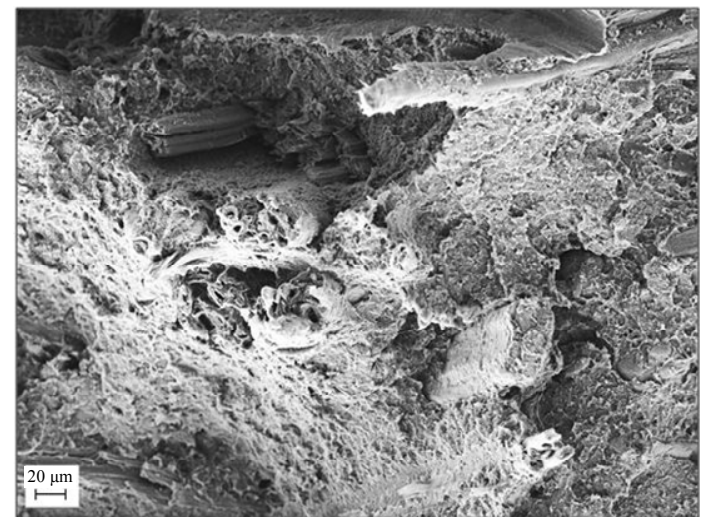

(a) shown and is more refined with the addition of PE- $g$-MA in the blend [33]. This might be due to the homogeneity of the blends caused by the enhanced adhesion between the fibers and HDPE in the presence of PE- $g$-MA. It is also observed that the layer of matrix material was also pulled out with the fibers during tensile fracture, which further substantiates the existence cohesive coupling between the fibers-HDPE added with PE-g-MA [18]. It is expected that the presence of PE- $g$-MA plays a signifycant role in promoting good interaction between the KF and the HDPE matrix. These observations are consistent with the mechanical properties observed, i.e., the composites with PE- $g$-MA have a higher tensile strength than the system without PE- $g$-MA. The addition of PE- $g$-MA into the composites is expected to improve the adhesion and compatibility of the phases [11].

\section{Conclusion}

The effects of fiber treatment and loading on HDPE/KF composites were successfully studied with the addition of PE-g-MA as a compatibilizer. All composites were successfully prepared using a melt-blending process. HDPE/

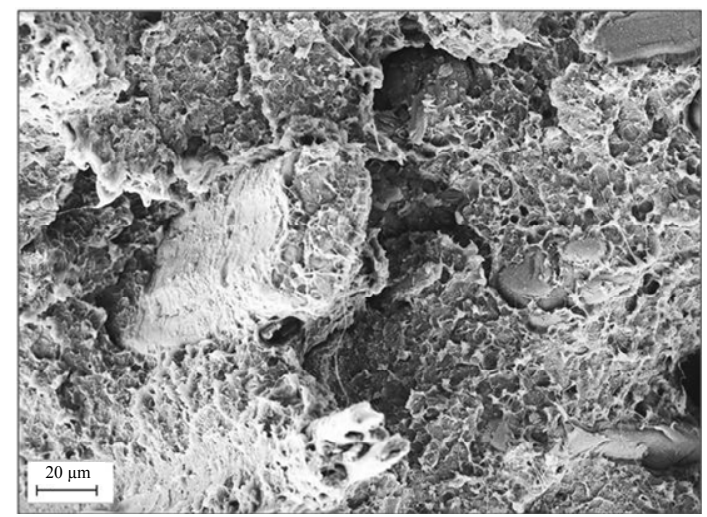

(b)

Figure 8. FESEM micrograph of a UKF composite at (a) $250 \times$ and (b) $500 \times$ magnification with PE-g-MA loading.

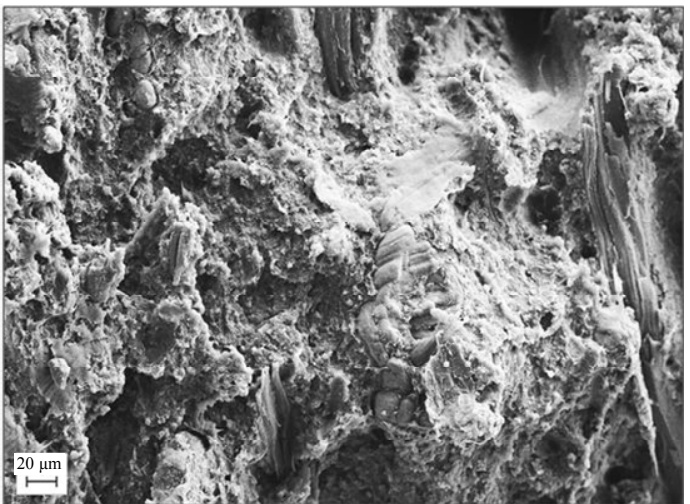

(a)

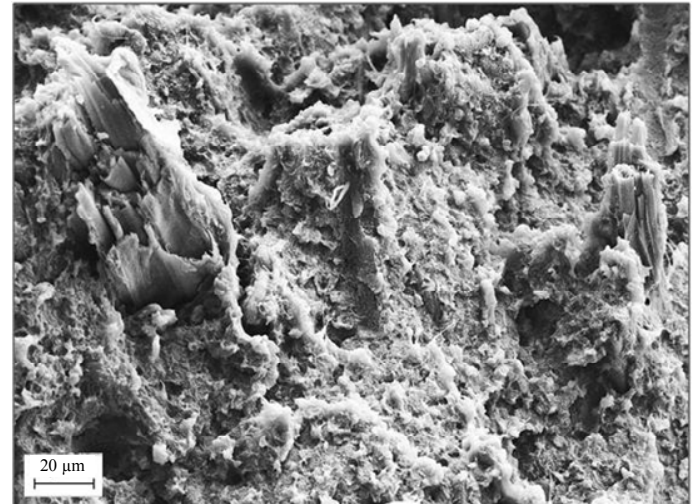

(b)

Figure 9. FESEM micrograph of a UKF composite at (a) $250 \times$ and (b) $500 \times$ magnification with PE-g-MA loading. 
TKF/PE- $g$-MA shows the highest value for $G$ ', $G$ ' and $\eta^{*}$, which were seen in the change in thermal stability with respect to HDPE and HDPE/PE- $g$-MA. The addition of KFs to HDPE and HDPE/PE-g-MA polymer matrixes changed the thermal decomposition. Studies on the effect of KF surface treatment on the tensile properties have been conducted and treated composites showed better mechanical properties compared to untreated fiber composites. It is also obvious that TKF reinforced with HDPE has better mechanical properties than untreated kenaf fiber. Composites prepared using $20 \%$ fiber loading showed optimum mechanical properties for both untreated and treated composites. The treated composites have more optimal results than the untreated composites, and the presence of PE-g-MA acts as a compatibilizer, improving the interaction between the filler and matrix.

\section{Acknowledgements}

The authors are grateful to the Ministry of Higher Education (MOHE) and the Ministry of Science, Technology \& Innovation, Malaysia (MOSTI) for sponsoring this research under their respective UKM-ST-07-FRGS00412009 and 05-01-02-SF1017 research grants. The authors wish to thank the management and staff members in the department of Chemical Sciences and Food Technology at Universiti Kebangsaan Malaysia for supporting this study. The authors lastly express thanks to the Universiti Kebangsaan Malaysia for economical support.

\section{REFERENCES}

[1] M. Avella, G. Bogoeva-Gaceva, A. Buzarovska , M. E. Errico, G. Gentile and A. Grozdanov, "Poly(lactic acid)Based Biocomposites Reinforced with Kenaf Fibers," Journal of Applied Polymer Science, Vol. 108, No. 6, 2008, pp. 3542-3551. doi:10.1002/app.28004

[2] J. R. Araujo, W. R. Waldman and M. A. De Paoli, "Thermal Properties of High Density Polyethylene Composites with Natural Fibres: Coupling Agent Effect," Polymer Degradation and Stability, Vol. 93, No. 10, 2008, pp. 1770-1775. doi:10.1016/j.polymdegradstab.2008.07.021

[3] N. Sgriccia and M. C. Hawley, "Thermal, Morphological, and Electricazation Characterization of Microwave Processed Natural Fiber Composites," Composites Science and Technology, Vol. 67, No. 9, 2007, pp. 1986-1991.

[4] A. Baurmaud and C. Baley, "Investigation on the Recycling of Hemp and Sisal Fibre Reinforced Polypropylene Composites," Polymer Degradation and Stability, Vol. 92, No. 6, 2007, pp. 1034-1045. doi:10.1016/j.polymdegradstab.2007.02.018

[5] N. Sgriccia, M. C. Hawley and M. Misra, "Characterization of Natural Fiber Surfaces and Natural Fiber Composites," Composites Part A: Applied Science and Manufacturing, Vol. 39, No. 10, 2008, pp. 1632-1637.

[6] S. Mir, T. Yasin, T. J. Halley, H. M. Siddiqi and T.
Nicholson, "Thermal, Rheological, Mechanical and Morphological Behavior of HDPE/Chitosan Blend," Carbohydrate Polymers, Vol. 83, No. 2, 2011, pp. 414-421. doi:10.1016/j.carbpol.2010.07.069

[7] M. Hetzer and D. D. Kee, "Wood/Polymer/Nanoclay Composites, Environmentally Friendly Sustainable Technology: A Review," Chemical Engineering Research and Design, Vol. 86, No. 10, 2008, pp. 1083-1093. doi:10.1016/j.cherd.2008.05.003

[8] S. Ochi, "Mechanical Properties of Kenaf Fibers and Kenaf/PLA Composites," Mechanics of Materials, Vol. 40, No. 4-5, 2008, pp. 446-452. doi:10.1016/j.mechmat.2007.10.006

[9] M. C. N. Yemele, A. Koubaa, A. Clautier, P. Soulounganga and M. Wolcott, "Effect of Bark Fiber Content and Size on the Mechanical Properties of Bark/HDPE Composites," Composites: Part A, Vol. 41, No. 1, 2010, pp. 131137. doi:10.1016/j.compositesa.2009.06.005

[10] D. W. Chae, K. J. Kim and B. C. Kim, "Effect of Silicate-1 Nanoparticles on Rheological and Physical Properties of HDPE," Polymer, Vol. 47, No. 10, 2006, pp. 36093615. doi:10.1016/j.polymer.2006.03.053

[11] Y. Lei, Q. Wu, F. Yao and Y. Xu, "Preparation and Properties of Recycled HDPE/Natural Fiber Composites," Composites Part A: Applied Science and Manufacturing, Vol. 38, No. 7, 2007, pp. 1664-1674. doi:10.1016/j.compositesa.2007.02.001

[12] F. P. L. Mantia, M. Monreale and Z. A. M. Ishak, "Effect of Glass Fiber Hybridization on Properties of Sisal FiberPolypropylene Composites," Journal of Applied Polymer Science, Vol. 40, No. 7, 2005, pp. 623-627.

[13] J. Mirbagheri, M. Tajvidi, J. C. Hermanson and I. Ghasemi, "Tensile Properties of Wood Flour/Kenaf Fiber Polypropylene Hybrid Composites," Journal of Applied Polymer Science, Vol. 105, No. 5, 2007, pp. 3054-3059. doi:10.1002/app.26363

[14] K. C. M. Nair, R. P. Kumar, S. Thomas, S. C. Schit and K. Ramamurthy, "Rheological Behavior of Short Sisal Fiber-Reinforced Polystyrene Composites," Composites Part A: Applied Science and Manufacturing, Vol. 31, No. 11, 2000, pp. 1231-1240. doi:10.1016/S1359-835X(00)00083-X

[15] C. F. Liu, R. Sun, M. Qin, A. Zin, J. Ren, F. Xu, J. Ye and $\mathrm{S}$. Wu, "Chemical Modification of Ultrasound-Pretreated Sugarcane Bagasse with Maleic Anhydride," Industrial Crops and Products, Vol. 26, No. 2, 2007, pp. 212-219. doi:10.1016/j.indcrop.2007.03.007

[16] S. Alix, E. Philippe, A. Bessadok, L. Lebrun, C. Morvan and S. Marais, "Effect of Chemical Treatments on Water Sorption and Mechanical Properties of Flax Fibres," Bioresource Technology, Vol. 100, No. 20, 2009, pp. 4742-4749. doi:10.1016/j.biortech.2009.04.067

[17] P. J. Herrera-Franco and A. Valades-Gonzalez, "A Study of the Mechanical Properties of Short Natural-Fiber Reinforced Composites," Composites Part B: Engineering, Vol. 36, No. 8, 2005, pp. 597-608. doi:10.1016/j.compositesb.2005.04.001

[18] S. Mohanty, S. Verma and S. K. Nayak, "Dynamic 
Mechanical and Thermal Properties of MAPE Treated Jute/HDPE Composites," Composites Science and Technology, Vol. 66, No. 3-4, 2006, pp. 538-547. doi:10.1016/j.compscitech.2005.06.014

[19] A. F. Vargas, V. H. Orosco, F. Rault, S. Giraud, E. Devaux and B. L. López, "Influence of Fiber-Like Nanofillers on the Rheological, Mechanical, Thermal and Fire Properties of Polypropylene: An Application to Multifilament Yarn," Composites: Part A, Vol. 41, No. 12, 2010, pp. 1797-1806. doi:10.1016/j.compositesa.2010.08.018

[20] M. Modesti, A. Lorenzetti, D. Bon and S. Besco, "Thermal Behaviour of Compatibilised Polypropylene Nanocomposite: Effect of Processing Condition," Polymer Degradation and Stability, Vol. 91, No. 4, 2006, pp. 672-680. doi:10.1016/j.polymdegradstab.2005.05.018

[21] T. Yan, Y. Xu and C. Yu, "The Isolation and Characterization of Lignin of Kenaf Fibers," Journal of Applied Polymer Science, Vol. 114, No. 3, 2009, pp. 1896-1901. doi:10.1002/app.29881

[22] A. M. M. Edeerozey, H. M. Akil, A. B. Azhar and M. I. Z. Ariffin, "Chemical Modification of Kenaf Fibers," Materials Letters, Vol. 61, No. 10, 2007, pp. 2023-2025. doi:10.1016/j.matlet.2006.08.006

[23] H. Anuar, S. H. Ahmad, R. Rashid, A. Ahmad and W. N. W. Busu, "Mechanical Properties and Dynamic Mechanical Analysis of Thermoplastic-Natural-Rubber-Reinforced Short Carbon Fiber and Kenaf Fiber Hybrid Composites," Journal of Applied Polymer Science, Vol. 107, No. 6, 2008, pp. 4043-4052. doi:10.1002/app.27441

[24] I. Ahmad, P. Y. Wong and I. Abdullah, "Effect of Fiber Composition and Graft-Copoly(ethylene/maleic anhydride) on Thermoplastic Natural Rubber Composites Reinforced by Aramid Fiber," Polymer Composites, Vol. 27, No. 4, 2006, pp. 395-401. doi:10.1002/pc.20225

[25] A. Vesterinen, S. Lipponen, J. Rich and J. Seppälä, "Effect of Block Composition on Thermal Properties and Melt Viscosity of Poly[2-(dimethylamino)ethyl methacrylate], Poly(ethylene oxide) and Poly(propylene oxide) Block Co-Polymer," Express Polymer Letter, Vol. 5, No. 9, 2011, pp. 754-765. doi:10.3144/expresspolymlett.2011.74
[26] M. Z. Pan, S. Y. Zhang and D. G. Zhou, "Preparation and Properties of Wheat Straw Fiber-Polypropylene Composites. Part II. Investigation of Surface Treatments on the Thermo-Mechanical and Rheological Properties of the Composites," Journal of Composite Material, Vol. 44, No. 9, 2010, pp. 1061-1074. doi:10.1177/0021998309349549

[27] S. H. Tabatabaei, P. J. Carreau and A. Ajji, "Rheological and Thermal Properties of Blends of a Long-Chain Branched Polypropylene and Different Linear Polypropylenes," Chemical Engineering Science, Vol. 64, No. 22, 2009, pp. 4719-4731. doi:10.1016/j.ces.2009.04.009

[28] A. Durmus, A. Kasgoz and C. W. Marcosko, "Linear Low Density Polyethylene (LLDPE)/Clay Nanocomposites. Part 1: Structural Characterization and Qualifying Clay Dispersion by Melt Rheology," Polymer, Vol. 48, No. 15,2007 , pp. 4492-4502.

doi:10.1016/i.polymer.2007.05.074

[29] E. Tronc, C. A. Hernández-Escobar, R. Ibarra-Gómez and A. Estrada-Monje, "Blue Agave Fiber Esterification for the Reinforcement of Thermoplastic Composites," Carbohydrate Polymers, Vol. 67, No. 2, 2007, pp. 245-255. doi:10.1016/j.carbpol.2006.05.027

[30] C. Tan, I. Ahmad and M. Heng, "Characterization of Polyester Composites from Recycled Polyethylene Terephthalate Reinforced with Empty Fruit Bunch Fibers," Materials and Design, Vol. 32, No. 8-9, 2011, pp. 44934501. doi:10.1016/j.matdes.2011.03.037

[31] M. S. Jamil, I. Ahmad and I. Abdullah, "Effect of Rice Husk Filler on the Mechanical and Thermal Properties of Liquid Natural Rubber Compatibilized High-Density Polyethylene/Natural Rubber Blends," Journal of Polymer Research, Vol. 13, No. 4, 2006, pp. 315-321. doi:10.1007/s10965-005-9040-8

[32] H. Liu, Q. Wu and Q. Zhang, "Preparation and Properties of Banana Fiber-Reinforced Composites Based on High Density Polyethylene (HDPE)/Nylon-6 Blends," Bioresource Technology, Vol. 100, No. 23, 2009, pp. 60886097. doi:10.1016/j.biortech.2009.05.076

[33] K. Jarukumjorn and N. Suppakarn, "Processing and Mechanical Properties of Organic Filler-Polypropylene Composites," Composites: Part B, Vol. 96, No. 5, 2009, pp. 1906-1913. 